Article

\title{
The Effect of Patient Participation through Physician's Resources on Experience and Wellbeing
}

\author{
Jiyoung Kim \\ Cornell Institute for Healthy Futures, Cornell University, Ithaca, NY 14853, USA; jk2868@cornell.edu; \\ Tel.: +1-607-229-9835
}

Received: 6 April 2018; Accepted: 17 June 2018; Published: 20 June 2018

\begin{abstract}
Few studies have reported on how customer value is co-created in healthcare service delivery, and its effect on patients' perceptions of wellbeing. It is important to examine physician-patient interaction in the context of a healthcare sector characterized by complex, specialized services and to determine how value is thereby co-created. This study's purpose is to investigate the potential impact of patient participation through physicians' resource offering on patient experiential value and wellbeing. Data was collected through a questionnaire survey of actual patients in South Korea, whose responses were analyzed via structural equation using IBM SPSS Statistics for Windows, Version 22.0. IBM Corp.: Armonk, NY, USA. The results indicate that physicians provide significant affective and cognitive resources to patients; in turn, patients are actively involved in the medical encounter process. These co-creation activities lead to increases in patients' experiential value and perceived wellbeing. Patients' play a major role in problem-solving, and service providers contribute resources such as professional expertise and affective care. Healthcare service providers can refer to the service process model proposed herein and aim to maximize patients' roles and use of their resources for patients' wellbeing.
\end{abstract}

Keywords: customer value co-creation; physician's resource offering; customer participation; experience value; wellbeing; healthcare service

\section{Introduction}

Recent studies on transformative services, a topic gaining increasing attention from researchers, focusses on healthcare services and recognizes the industry's great potential to improve individuals' wellbeing and welfare $[1,2]$. Customers in healthcare service have traditionally been viewed as passive participants. Reflecting the expertise of physicians, they inevitably have less control over information than physicians [3]. In recent years, however, healthcare services have emphasized that to successfully recover from chronic diseases, patients must cooperatively interact with physicians and be actively involved in service process [4-6]. It has also been reported that, in the course of discussing and selecting an optimal treatment process, it is beneficial for the patient to actively inform the physician of their condition and environment, and for the physician to effectively provide various resources to improve the patient's satisfaction [5-7]. In this study, we expand patient value co-creation and service experience research by investigating the potential impact of patient participation through physicians' resource offering to improve patient experiential value and wellbeing.

Healthcare services are complex and specialized, so it is important to closely examine the interaction between patient and physician, and how customers' value is thereby co-created [8]. Both service providers and customers rely heavily on the knowledge and resources provided by the other $[9,10]$. Thus, the creation of value through the interaction between physician and patient is essential in healthcare service management [11], and the wide range of interactions and collaborations between physicians and patients is a major factor in complex and sophisticated service exchange 
situations such as in healthcare. For services based on expertise, such as in healthcare, service delivery is a type of problem-solving process [12,13] that involves identifying the customer's needs, defining objectives, and determining how to achieve them [13]. At times, a service provider's high expertise causes a disparity between them and service users, who may face difficulty in clearly identifying what they want [14]. In such cases, the user is entirely dependent on the expert to diagnose and identify the problem [10]. Consequently, this imbalance can cause difficulties within service situations. Accordingly, such aspects as the flexibility, responsiveness, reliability, and communication skills of experts are important resources in providing such services $[15,16]$.

According to previous studies, value co-creation consists of four major types; engagement and collaboration for resource integration between companies and customers [5,17], dialogical interactions that listen to the customer's voice to identify their hidden needs and wants [18], the way the firm-providers learn from customers by inducing customers' valuation through messages, reviews and references [19] and creative processes stemming from shared thinking, engaging conversations, and shared issues [20]. Thus, integrating resources such as dialogical interactions, and shared thinking are critical components for both of customers and service providers to enhance service experience. Focusing on customers' value co-creation in healthcare services, McColl-Kennedy et al. [5] and, Sweeney et al. [6] argue that collaboration with medical teams through customer involvement in health care enhances patients' perceived wellbeing. This study, however, focused on out-of-clinic activities (i.e., at home and community) rather than medical encounters. Recently, McColl-Kennedy et al. [21] demonstrated that interactions with medical staff improve customers' wellbeing through behavior changes. However, these interactions measured social perspectives and did not evaluate the customer's experiential value, which is for the actual core service delivery process.

As such, this study addresses the following research questions: (1) how can physicians' resource offerings help patients participate in medical encounters? (2) how can patients' participation influence their experiential value, in turn, perceived wellbeing? This study contributes to extant literatures in two aspects. This study suggests a research model which focuses on how physicians 'resource offering can help patients overcome their passivity in medical encounters and gain experiential value and perceived wellbeing. This study also identifies the types of resource offering from physicians to patients related to patients' experiential values upon existing studies.

\section{Theory and Hypotheses}

\subsection{Characteristics of Healthcare Service Encounters: Relationship between Physician and Patient}

Healthcare service providers are not limited to physicians. The term encompasses a wide array of individuals who interact directly with patients including physicians, nurses, other medical professionals, counselors, therapists, and administrative staff. While each role contributes to team efforts to provide healthcare services, patients spend more time with physicians than any other team members in the decision-making process relating to their health. In a healthcare service encounter, the physician and patient engage in a face-to-face relationship, and patients often meet regularly with the same physician over time, frequently resulting in very intimate interactions [5]. However, even where a patient regularly sees the same doctor, the service outcome changes depending on the patient; thus, a patient's active participation is an essential factor in achieving a successful service outcome [5]. Moreover, healthcare services are generally very complex and, depending on the type and severity of the health condition, may be comprised of several stages [22]. Sometimes patients' unrealistic or erroneous expectations raise a situation's difficulty [23].

In this context, the extensive exchange of information and empathy deepens the relationship between physician and patient. This leads to interactions between physicians and patient that affects the latter's evaluation of the service [24]. According to social cognitive theory, social factors experienced during points of contact are essential to creating physician/patient relationships. These factors include trust, interest, communication, and attention Research on healthcare service encounters has emphasized 
that physicians should provide appropriate emotional care in addition to care and treatment based on their technical expertise [24]. Social cognitive theory also suggests that patient satisfaction depends on how the patient interprets point-of-contact interactions [25,26], and this is key to virtually all services provided [27]. Thus, the cooperative interactions between physician and patient in medical encounters, in which they determine how to share and utilize resources, play a major role in creating value.

\section{2. "Value in Use" in Healthcare Services}

The concept of "value" has been widely discussed in service-related research. According to La Rocca and Snehota [28], value is associated with devising and creating solutions throughout the process of delivering products or services to customers. While most prior studies have focused on value in terms of efficiency, recent research has increasingly advocated discussing value in terms of not only economic utility but also customer experience [29]. It is also important for the service provider to understand how the customer perceives the value they seek to gain from the service [30], which ultimately increases the customer's experiential value and perceived wellbeing [31,32].

Since value is created simultaneously by both the service provider and customer, the impact of the information on situation or context shared by each party is significant [33,34]. This information is related to service participants' understanding of prior knowledge and future outcomes [28]. The success of service exchanges is determined by their participants, and all parties contribute to value creation [35]. Consequently, the patient's perceived value of service encounters results from contextual perception, which is dependent on the situation and socially conceptualized [36,37].

On the other hand, the notion of customer value can be defined as a cost-based outcome [38], and customers form value concepts by assessing the benefits to be gained from their efforts [39]. However, the customer's perceived value is, in fact, largely determined by their experiences at service contact points [40]. In other words, value is part of the service delivery process, and when considering the many complex relationships between physicians and customers [41,42], value varies depending on how the customer perceives the delivery process during individual service encounters [43]. Therefore, how each customer interacts with their physician profoundly affects how they understand and experience the mechanism and structure of the service process [44,45].

\subsection{Resources from Physician to Patient}

Grönroos and Voima [46] state that value is the most misleading concept in service marketing and management. Defining how customer value is formed is among the most controversial topics in the field [36]. Grönroos and Voima [10] propose that value creation in a service occurs solely in the dynamic common domain between the service provider and customer. This area is largely based on communication. In a simple healthcare service encounter, the patient may be exposed to various physicians and affected by various factors such as the physicians' knowledge and skills, the patient's own personal characteristics, and the situation [36]. Thus, similar to other service industries, cooperative value is created through interactions within this common domain.

Examining what value means to the patient is identifying how to share and utilize resources through interactions in service encounters [30,47]. Service-dominant logic is based on a common mission between the service provider and customer, and the complex complementarities between them [12]. Therefore, cooperative value creation between the physician and patient in healthcare service encounters needs to be examined in terms of resource integration. Therefore, this study aims to investigate how physicians' resource offering impacts the patient-centered participation behavior of physicians and patients at healthcare service contact points $[47,48]$. This relation will ultimately demonstrate the collaborative value-creation process and the interactions between physicians and patients in the common domain proposed by Grönroos and Voima [46].

Customers gain benefit from actively participating in the service process. The customers' engagement process for services is value co-creation, which works in a variety of forms; a function of interaction [19], integration, relationship, participation and involvement [6,8]. Customer service experience results from 
value co-creation and is multi-dimensional; cognitive, social, physical, psychological and economical. These can be largely divided into cognitive and affective dimensions $[15,16]$. On the other hand, the resources that physician provide to patients in the service delivery process can be largely divided into cognitive and emotional resources [4], and in the end, the value that patients experience is associated with them (See Figure 1). Therefore, this study proposes that physicians' resources offerings lead to customer participation, and this value co-creation is given to the customer as a perceived value.

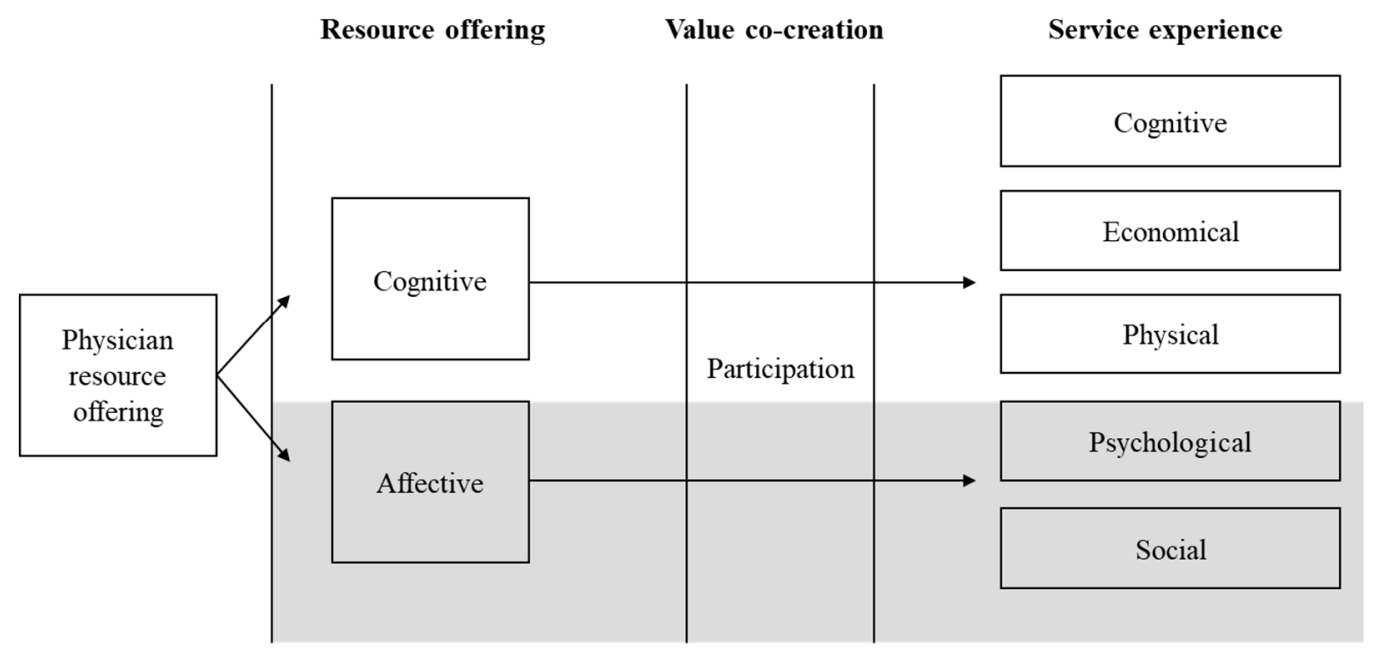

Figure 1. Theoretical framework.

\subsection{Physician's Resource Offering and Patient's Participation}

When the service provider actively converses, and interacts with the customer, the latter's perception of service value is positively influenced [12]. In addition, prior research indicates that customer value can be co-created through key information sharing and efficient interactive dialogue $[49,50]$. Physicians can only rely on information provided by patients with regard to such factors as their needs, demands, and usage situation $[13,14]$. However, efficient conversations can be particularly difficult, especially in the context of professional and complex services such as healthcare because patients experience an information imbalance and uncertainty in relation to the physician [51]. The greater the information imbalance between service providers and customers, the more likely they are to depend on each other for value creation [52].

Thus, the physician needs to provide a comfortable atmosphere and instill a sense of security in the patient to encourage his/her active participation in the service process. Cooperative and empathic communication between physicians and patients positively influences the patient's participation in the service decision-making process [9]. Service contact provides many means for engagement among participants [12]. In healthcare services particularly, major affective resources such as empathy and care can play decisive roles. Patients can participate more actively in the service process when they feel their physician is empathic and genuinely interested [30,53]. Ultimately, the physician's medical practice should be interactive, connected to the patient, and based on emotional care; this, in turn, affects the patient's perceived value of the experience.

Hypothesis 1 (H1). The physician's affective resource offering will have a positive impact on patient participation.

The service process also involves collaborative activities and resource integration involving all participants in the exchange [54]. For healthcare services, the information a physician provides to the patient is essential for joint decision making. When the physician provides a large amount of information during the service encounter, the patient participates by also providing information, thereby generating significant satisfaction from the interaction [55] that ultimately impact service 
outcomes. For professional services, the role of cognitive resources is significant; in healthcare, these resources include the expertise and knowledge provided by the physician. This cognitive resource-based exchange process helps patients develop confidence and trust in healthcare services through a series of interactive exchanges among participants [56].

Another important determinant of the patient's active participation in the service process is their confidence in the physician. In healthcare services, a patient's trust in a physician indicates that the physician has a considerable level of expertise and skill, that the patient believes in and relies on the physician's judgment, and that they feel assured when receiving the service from the physician [57]. In other words, it indicates the patient's expectations of the physician and confidence in him/her to deliver. Thus, patient confidence and trust, based on the physician's professional skills, knowledge, and cognitive resources, affect the patient's experience. Patients have previously been found more likely to actively participate in healthcare services if they had confidence in their physician, developed through cooperative interactions [58].

Value co-creation at contact points requires active participation from each participant [55], particularly when making decisions about treatment methods during a healthcare service interaction [59]. Healthcare services' special purpose is to consider the treatment of diseases and subsequently decide how to conduct the treatment, which should be a joint decision-making process. In other words, the physician should provide enough information about the pros and cons of each treatment method in a manner easy for the patient to understand; then, an optimal treatment plan is decided with the patient according to their preference. This requires a high level of trust, and an intimate relationship between the physician and the patient. In addition, the physician and patient should provide each other with detailed information necessary for decision making. In recent years, it has become necessary for patients to present their preferences and opinions in a very detailed and intimate way [60]. That is, patient confidence and ideas should be discovered and integrated within the service provider's strategy $[9,60,61]$. Involving patients in joint decision making for treatment and recovery methods is also a form of accountability.

Many studies have indicated that increased cooperative interactions between physicians and patients increases the likelihood that patients will follow physician instructions and actively participate in medical process [62-65]. Furthermore, when information is shared in a timely manner, the patient can have confidence in the physician's expertise and skills [66]. In other words, in the healthcare service process, the information that physicians and patients share through collaborative interactions can help the patient to actively participate in a medical service process, establishing the physician's professional skills.

Hypothesis 2 (H2). The physician's cognitive resource offering will have a positive impact on patient participation.

\subsection{Patient's Experiential Value and Wellbeing}

Previous research on customer experience has interpreted customer experience as their evaluation of a service or product [67]. However, in value co-creation, customer experience is evaluated through a variety of perspectives on value [10], and is deemed an evaluation of past or future interactions [36]. Therefore, the nature of various interactions and contexts in value creation is a key factor in understanding customer experience [31].

Additionally, service participants including both customers and service providers offer and accept their respective resources with expectations regarding the output [31,47]. In other words, experiential value is complex, subjective, and multi-faceted [68], while Holbrook [67] claims that value is relative preference based on interaction. Essentially, value is the collection of all feelings, thoughts, expectations, sensations, imaginations, and behaviors of the experiencing individual. Therefore, the level of customer experience depends upon the degree of their participation in the service [68]. Further, it has been suggested that customer participation affects perceived service quality and value creation, which in turn affects service outcomes such as customer experience [69]. 
Customer experience is an affective/cognitive response to the service process [70]. At service contact points, customer experience is particularly influenced by the quality of interaction between the service provider and the customer. According to social cognitive theory, social information is obtained through interaction; this is especially applicable to healthcare services due to the information imbalance between the physician and patient, as well as the need for extensive human interactions [71], whose importance is increased by patient stress [72]. Therefore, when the social factors a patient expects are found in his/her interaction with the physician and resources are exchanged, the patient will assess the interaction more favorably [72]. This does not seem to be influenced by the severity of the patient's illness or the degree of professionalism [73]. By participating more actively in the service process, patients feel more comfortable and reduce stress through a satisfying contact experience [74], leading to satisfactory outcomes such as referrals and further revisit intentions [8].

Healthcare services can improve a patient's quality of life by increasing their life satisfaction, happiness, and psychological wellbeing [2]. Customer participation in value co-creation signifies devoting time and effort to the service process by sharing and suggesting information or participating in the decision-making process [11,46]. Therefore, in the healthcare service industry, to successfully treat chronic diseases such as cancer, individuals must cooperatively interact with physicians and actively participate in the service process [6-8]. Furthermore, in the process of discussing and choosing the optimal treatment, the patient should actively inform the physician of their condition and environment [9]. In other words, patients can increase life satisfaction by actively participating in the service process [7]. Therefore, it is further hypothesized that if the patient actively participates in a medical encounter, his/her experiential value and wellbeing perception will also increase. The proposed model is shown in Figure 2.

Hypothesis 3 (H3). The degree of patient participation will be positively related to the patient's experiential value.

Hypothesis 4 (H4). The degree of patient participation will be positively related to the patient's perceived wellbeing.

Hypothesis 5 (H5). The degree of the patient's experiential value will be positively related to their perceived wellbeing.

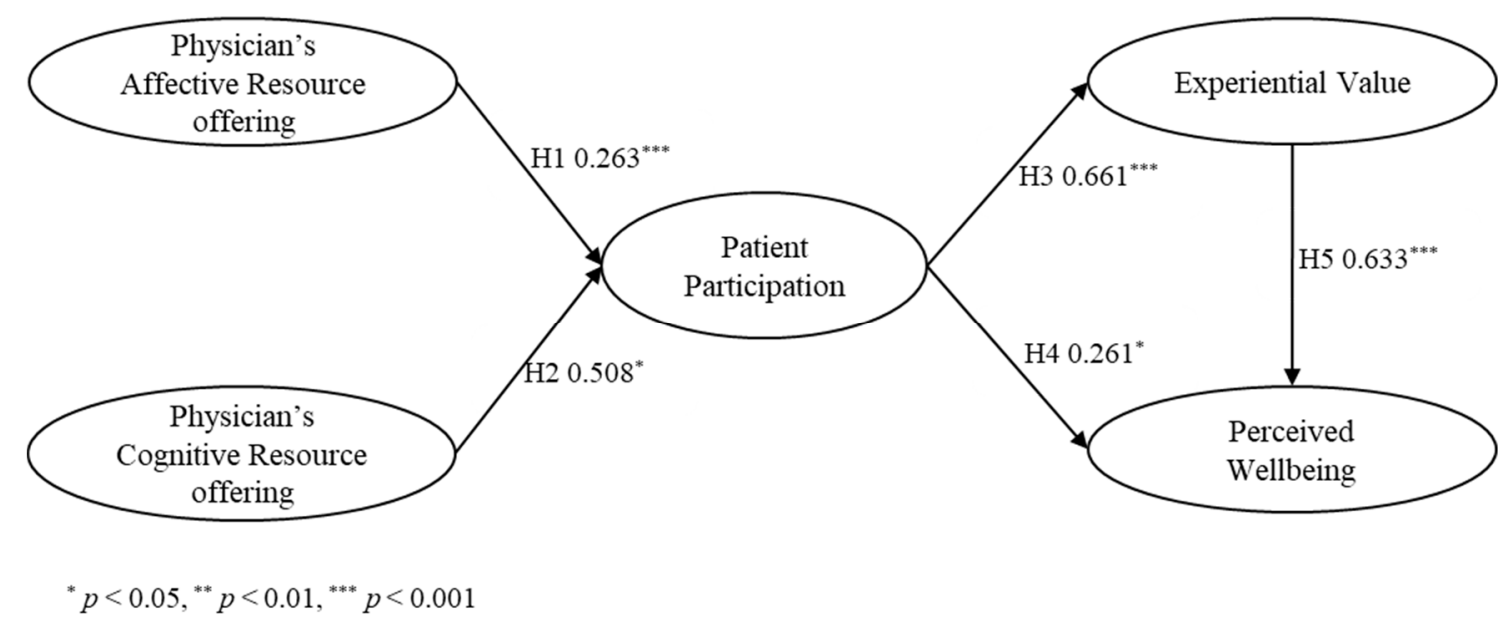

Figure 2. Research model with results.

\section{Research Method}

\subsection{Preliminary Study}

In order to achieve research objectives, firstly this study undertook an exploratory approach as a preliminary study before empirically testing the proposed model. The purpose of this preliminary study is to reaffirm the proposed model through interviewing actual patients. Accordingly, eight 
healthcare customers who have visited hospitals in 6 months were interviewed. Respondents profiles are as follows; Age: 20-50s, Sex: 5 females, 3 males, Clinic used: 4 orthopedics, 4 internal medicine. Respondents were asked to recall and describe followings; (1) Situations where patient-physician interaction affected their experience of the service (2) To elaborate on the reasons why that happened; (3) How the incident affected their experience, and feelings. The abductive reasoning approach in analyzing the data was used. Thematic analysis was used by ascribing meanings to the incidents and categorizing these incidents [74].

As a result, the findings of the pre-study recognize that patients' resource offering to patients can be categorized mainly into cognitive and affective types. Further, the result identifies these cognitive and affective value-creating activities that benefit each patient's experience and feelings. The cognitive and affective resource from physicians has offers details as follows.

[Affective resource from physicians to patients]

"The doctor were totally close to me. And if I have any special request, he tried to fulfill anything"

"The doctor was very nice and friendly. It was very nice that the physician recalled me, thus I did not have to get annoyed and could relax"

Negative. "I visited the doctor at that time he was not engaging. The doctor didn't talk into my eyes and said in a very small voice. When I did not hear him well and asked him again, he responded in annoyed"

[Cognitive resource from physicians to patients]

"The treatment was very efficient and professional. When I came back home, I don't feel any doubt and worry"

"The doctor gave me very concrete information of what's going on, and it got rid of unnecessary guess and doubt"

"He explained the need for additional tests and I could make decisions accordingly"

\subsection{Method and Participants}

This study selected patients who visited healthcare institutions to examine the cooperative value creation process between patients and physicians in healthcare service encounters. We chose an orthopedic hospital in a metropolitan area of South Korea, specializing mainly in treating chronic diseases as the context of this study. The selected hospital has a multidisciplinary team comprised of doctors, nurses, physiotherapists, occupational therapists, etc. In addition to focusing on physical recovery, its treatment also aims include the patient's psychological and social functioning after the completion of acute care. There has been a recent increase in the number of cases of neurological, circulatory, and musculoskeletal diseases; thus, the number of patients receiving rehabilitation is also rising.

This study surveyed outpatients over 20 years of age who participated in healthcare service encounters at the hospital. A self-survey technique was utilized for data collection. Unconscious patients, patients with severe psychiatric symptoms (including dementia), and those unable to communicate were excluded. The survey period was kept as short as possible to minimize the influence of various uncontrollable exogenous variables. Patients meeting the pre-determined participation criteria were informed of the study's purpose and asked to provide their written consent to participate. Those who did so were given a structured questionnaire, which they were asked to complete themselves.

In total, 230 individuals were surveyed, 194 of whom returned, representing a valid response rate was $77.6 \%$. Based on the responses of these 194 patients, a sample descriptive analysis showed that $35.7 \%$ of the participants were female. In terms of age, $68.5 \%$ of respondents are in their $30-40 \mathrm{~s}$. 


\subsection{Metrics}

The detailed items were measured through higher-level concepts, such as physician resources offering (cognitive and affective), patient participation, patient's experience value, and patient's behavioral intention during the physician-patient interaction. All items were sourced from the existing literature, especially empirical studies on healthcare service situations. The items were scored on a seven-point Likert scale ( $1=$ not at all, 7 = very much so). In addition, general characteristics such as age, gender, and occupation were also surveyed.

First, the collaborative value creation process between the physician and patient was conceptualized as the physician's affective and cognitive resource offering and patient participation [48]. The physician's affective resource provision measures three items, namely, whether the physician was friendly, empathetic to their condition, and demonstrated an understanding of their specific needs. Three items were measured to evaluate the physician's cognitive resource provision: whether the physician provided sufficient medical knowledge, explained a prescription or a treatment method, and the degree to which the physician discussed his suggestions with patients [21,48].

The degree of patient participation was assessed using standards presented by Gallan et al. [68], comprised of three measures: The patient actively shared information with their doctor, made considerable effort to discuss their condition with their doctor, and worked hard to participate in their care. The patient's experiential value was measured by whether use of the hospital services was comfortable, whether services were memorable, and whether their interaction with physicians was positive [56]. Finally, the patient's perceived wellbeing was measured by how they responded to the following items: satisfaction with quality of life, happiness with quality of life, and sense of wellbeing [75]. This measure drew on Sweeney et al.'s items [8] regarding healthcare services.

\section{Results}

\subsection{Reliability and Validity of the Measured Variables}

Confirmatory factor analysis was performed by applying a maximum likelihood estimation using AMOS 20.0. The model structure's fit index was $\chi^{2}=102.337, \mathrm{df}=79, p<0.04, \mathrm{CFI}=0.988, \mathrm{GFI}=0.934$, $\mathrm{NFI}=0.948, \mathrm{RMSEA}=0.040$. To verify the reliability and validity of the confirmatory factor analysis, it was confirmed that standardized factor loadings were more than 0.7 and that the average variance extracted (AVE) for each variable was 0.5 or more, based on Fornell and Lacker [76]. Composite reliability (CR) exceeded the reference value by more than 0.6 , confirming internal consistency [77]. These results are summarized in Table 1. In addition, each factor load was significant, and regarding discriminant validity, it was confirmed that the AVE of the constructs was greater than the square of the correlation coefficient of potential factors, as shown in Table 2.

Table 1. Confirmatory Factor Analysis Results.

\begin{tabular}{cccccc}
\hline Variable & CFA Loading & t-Value & Cronbach's $\alpha$ & C.R. & A.V.E. \\
\hline Physician's affective & 0.829 & & & & \\
resource offering & 0.940 & 17.075 & 0.942 & 0.944 & 0.785 \\
& 0.921 & 16.586 & & & \\
\hline Physician's cognitive & 0.872 & & & & \\
resource offering & 0.755 & 10.317 & 0.903 & 0.902 & 0.665 \\
& 0.852 & 13.942 & & & \\
\hline & 0.770 & & & & \\
Patient Participation & 0.785 & 10.837 & 0.881 & 0.880 & 0.605 \\
& 0.850 & 11.628 & & & \\
\hline & 0.767 & & & & \\
Experiential Value & 0.864 & 11.417 & 0.889 & 0.887 & 0.667 \\
& 0.656 & 8.840 & & & \\
\hline & 0.745 & & & & \\
\hline
\end{tabular}


Table 2. Discriminant Validity Assessment.

\begin{tabular}{cccccccc}
\hline Constructs & Mean & SD & $\mathbf{1}$ & $\mathbf{2}$ & $\mathbf{3}$ & $\mathbf{4}$ & $\mathbf{5}$ \\
\hline 1. Physician's affective resource offering & 5.65 & 1.29 & $\mathbf{0 . 8 6}$ & & & & \\
2. Physician's cognitive resource offering & 5.70 & 1.18 & 0.80 & $\mathbf{0 . 8 7}$ & & & \\
3. Patient Participation & 5.66 & 1.31 & 0.42 & 0.46 & $\mathbf{0 . 8 9}$ & & \\
4. Experiential Value & 5.74 & 1.22 & 0.82 & 0.86 & 0.39 & $\mathbf{0 . 8 8}$ & \\
5. Patient Wellbeing & 5.64 & 1.45 & 0.80 & 0.83 & 0.38 & 0.82 & $\mathbf{0 . 8 9}$ \\
\hline
\end{tabular}

\subsection{Hypotheses Verification}

For each hypothesis test, the following fitness scores were considered acceptable: $\chi^{2}=112.029$, $\mathrm{df}=83, \mathrm{RMSEA}=0.043, \mathrm{NFI}=0.943, \mathrm{CFI}=0.985$, and GFI $=0.929$. The results for each hypothesis are summarized in Table 3, and the main findings are as follows. First, both physician's affective and cognitive resource offering to patients have a positive effect on patient participation. For Hypothesis 1 , the standardized coefficient value is 0.263 and the $t$ value is 2.267 , significant at the level $p<0.001$. For Hypothesis 2, the standardized coefficient value is 0.508 and the $t$-value is 4.104 , significant at $p<0.05$. This confirms that affective and cognitive resource from physicians are positively related to patient participation. Patients were more likely to actively participate in the decision-making process and follow-up steps suggested by the physician such as treatment methods when they judged that the physician was adequately providing cognitive or affective resources.

The second main finding is that patient participation had a positive effect on the patient's experiential value (standardized coefficient $=0.661$, $\mathrm{t}$-value $=7.315$ ). Patient participation also had a significant positive effect on the patient's perceived wellbeing (standardized coefficient $=0.261$, $\mathrm{t}$-value $=2.869$ ). In other words, the more actively patients participate in healthcare service encounters, the greater their perceived enjoyment of and satisfaction with the service. In addition, this has a positive effect on the patient's perceived wellbeing with regard to satisfaction with and pleasant feelings about one's life (standardized coefficient $=0.633$, $\mathrm{t}$-value $=6.022$ ).

Table 3. Hypotheses Test Results.

\begin{tabular}{cccc}
\hline Hypothesis & From $\rightarrow$ To & $\begin{array}{c}\text { Standardized } \\
\text { Coefficient }\end{array}$ & t-Value \\
\hline Hypothesis 1 & physician's affective resource offering $\rightarrow$ patient participation & 0.263 & $2.267^{* * *}$ \\
Hypothesis 2 & physician's cognitive resource offering $\rightarrow$ patient participation & 0.508 & $4.104^{*}$ \\
Hypothesis 3 & patient participation $\rightarrow$ patient experience value & 0.661 & $7.315^{* * *}$ \\
Hypothesis 4 & patient participation $\rightarrow$ patient wellbeing & 0.261 & $2.869^{*}$ \\
Hypothesis 5 & patient experience value $\rightarrow$ patient wellbeing & 0.633 & $6.022^{* * *}$ \\
\hline & ${ }^{*} p<0.05,{ }^{* * *} p<0.001$. & &
\end{tabular}

\section{Discussion and Conclusions}

\subsection{Summary and Implications}

While the healthcare service industry recognizes the importance of customer participation [11,12], there is a lack of empirical evidence about the cooperative value creation process. The value experienced by customers during service depends on the exchange and integration of various resources from each participant in the service process. Each participant actively participates in the service process and promotes value creation by sharing and integrating their affective and cognitive resources. As a result, this study contributes to value co-creation, service experience and transformative service research by providing the following important implications.

Considering that providers of specialized services such as healthcare mainly lead the service delivery process due to their expertise and experience [14], this study divides physician resources into 
affective and cognitive resources, and demonstrates that their provision are prerequisite for the value creation process. Patients play a major role in the problem-solving process: patients can participate in this process by providing clear information on their expectations and situations to complement their service provider's resources such as accumulated expertise and professional capabilities. Furthermore, patient's experiential values increase when they are actively involved in the process of creating value propositions for problem solving. In healthcare, experiential value is just as important as the treatment outcomes, which are difficult for patients to accurately assess [57]. Experiential value is also meaningful because it has been shown to increase the patient's subjective well-being. In healthcare, these value components embody various solutions that increase patients' quality of life.

In this way, patients also play the role of resource integrators [33] in value co-creation; the extent to which they play this role is important [54]. Decision making on treatment and recovery methods, especially in healthcare services, is a key factor in patient-centered care [9]. Adherence to physician's instruction signifies that the patient has agreed to the burden of the disease and the effectiveness of the treatment in view of the severity of the illness [78]. Patients are, at times, uncertain about these complex criteria, and may not follow the physician's instructions [78].

Finally, it can be expected that providing a full resource of medical staff will result in dyadic value co-creation between patients and physicians. Qualitative interviews in this study confirmed that the resource offerings of medical staff were largely divided into two types, affective and cognitive, which affected patients' experience and feeling. Experience and feelings are fairly subjective, which ultimately affects the value co-creation activities of the participants [36]. Therefore, the provision of emotional and cognitive resources of the medical staff affects patient participation, and this dyadic value co-creation will affect the patient's subjective feelings and experience.

From a practical perspective, this study provides suggestions to healthcare service providers in the design and management of cooperative medical services. Healthcare service providers can refer to the service process model proposed herein and aim to maximize patients' roles and use of resources in problem solving. First, this study indicates that healthcare service encounters require such factors as collaborative resource integration, interaction, and active participation to achieve successful problem solving. Therefore, understanding the physician-patient interaction based on resource offering is an essential factor in identifying the optimal value for the patient. Thus, it is important to provide adequate and appropriate dialogue to enable collaboration, clarify what is not well understood, and consider whether an unexpected solution has been provided. There should be plenty of opportunities to clarify expectations and assumptions, to avoid conflicting values between physicians and patients.

Second, the results emphasize the importance of clarifying the use value in services, such as healthcare, that require professional skills and knowledge. It is important to fully engage the customer's hidden resources and to make the customer more active in the service process. This requires physicians to provide a variety of affective and cognitive resources such as concise and detailed medical information, and guidance on treatment or healing methods tailored to match the patient's level of understanding and confidence through affective care. These efforts are especially important when providing healthcare service because patients lack sufficient expertise to predict outcomes. It is not enough for physicians to merely explain their expertise, medical skills, etc.; rather, they must be aware of the need for cooperative interaction. Without this interaction, patients may experience low levels of use value, leading to dissatisfaction.

Designing the medical service environment requires improving the experience by considering these value-creating activities. In other words, it is necessary to improve the physical environment so that patients can contribute to the process alongside medical staff. Hence, service personnel and physical environment designers should keep in mind the importance of and opportunities to make these environmental improvements. Finally, it is necessary to inform and educate patients and their families and caregivers about the importance of voluntary value-creating activities. Medical staff 
should encourage patients to interact with other service participants to maintain good habits and positive attitudes.

\subsection{Limitations and Future Directions}

This study is limited as it only conducted research in one South Korean hospital. While this approach is advantageous in minimizing differences in the nature and severity of patients' diseases, the results cannot be generalized without applying the same method to participants in other situations. In addition, this study measured the degree of customer participation in a unidimensional measure, whereas some studies have segmented this construct. Therefore, further studies may consider segmenting the concept of customer participation into sub-dimensions to expand the research context. Furthermore, to increase the possibility of generalizing the results, it is necessary to conduct experimental research rather than only collecting survey data. Whereas the survey method depends on respondents' memories, an experiment would allow customer responses to be examined by manipulating the degree of the physician's resource provision.

Lastly, in relation to measurement items, this study measured the patient experience as a uni-dimension. As noted earlier in the theoretical framework, patient experience can be subdivided into various dimensions. Thus, further studies will provide a more specific view of the relationship among patient participant, patient experience, and patient well-being by measuring patient experiences with sub-dimensions.

Funding: This research received no external funding.

Acknowledgments: All sources of funding of the study should be disclosed. Please clearly indicate grants that you have received in support of your research work. Clearly state if you received funds for covering the costs to publish in open access.

Conflicts of Interest: The author declares no conflict of interest.

\section{References}

1. Bennett, J.; Rokas, O.; Chen, L. Sustainability healthcare in the smart home: A study of past, present and future. Sustainability 2017, 9, 840. [CrossRef]

2. Anderson, L.; Ostrom, A.L.; Corus, C.; Fisk, R.P.; Gallan, A.S.; Giraldo, M.; Williams, J.D. Transformative service research: An agenda for the future. J. Bus. Res. 2014, 66, 1203-1210. [CrossRef]

3. Ostrom, A.L.; Bitner, M.J.; Brown, S.W.; Burkhard, K.A.; Goul, M.; Smith-Daniels, V.; Rabinovich, E. Moving forward and making a difference: Research priorities for the science of service. J. Serv. Res. 2010, 13, 4-36. [CrossRef]

4. Holman, H.; Lorig, K. Patients as partners in managing chronic disease. Br. Med. J. 2000, 320, 526-527. [CrossRef]

5. McColl-Kennedy, J.R.; Vargo, S.L.; Dagger, T.S.; Sweeney, J.C.; van Kasteren, Y. Health care customer value cocreation practice styles. J. Serv. Res. 2012, 15, 370-389. [CrossRef]

6. Sweeney, J.C.; Danaher, T.S.; McColl-Kennedy, J.R. Customer effort in value cocreation activities improving quality of life and behavioral intentions of health care customers. J. Serv. Res. 2015, 18, 318-335. [CrossRef]

7. Hausman, A. Modeling the patient-physician service encounter: Improving patient outcomes. J. Acad. Mark. Sci. 2004, 32, 403-417. [CrossRef]

8. Grönroos, C. Value co-creation in service logic: A critical analysis. Mark. Theory 2011, 11, 279-301. [CrossRef]

9. Nordin, F.; Kowalkowski, C. Solutions offerings: A critical review and reconceptualization. J. Serv. Manag. 2010, 21, 441-459. [CrossRef]

10. Tuli, K.R.; Kohli, A.K.; Bharadwaj, S.G. Rethinking customer solutions: From product bundles to relational processes. J. Mark. 2007, 71, 1-17. [CrossRef]

11. Lindgreen, A.; Antioco, M.; Palmer, R.; Tim, V.H. High-tech, innovative products: Identifying and meeting customers' value needs. J. Bus. Ind. Mark. 2009, 24, 182-197. [CrossRef]

12. Lindberg, N.; Nordin, F. From products to services and back again: Towards a new service procurement logic. Ind. Mark. Manag. 2008, 37, 292-300. [CrossRef] 
13. Sawhney, M. Going beyond the Product: Defining, designing, and delivering customer solution. In The Service Dominant Logic of Marketing Dialog, Debate, and Directions; Lusch, R.F., Vargo, S.L., Eds.; M.E. Sharpe: New York, NY, USA, 2006; pp. 365-380.

14. Mitchell, V. Problems and risks in the purchasing of consultancy services. Serv. Ind. J. 1994, 14, 315-339. [CrossRef]

15. Lapierre, J. Customer-perceived value in industrial contexts. J. Bus. Ind. Mark. 2000, 15, 122-140. [CrossRef]

16. Liu, A.H. Customer value and switching costs in business services: Developing exit barriers through strategic value management. J. Bus. Ind. Mark. 2006, 21, 30-37. [CrossRef]

17. Vargo, S.L.; Lusch, R.F. Evolving to a new dominant logic for marketing. J. Mark. 2004, 68, 1-17. [CrossRef]

18. Ballantyne, D.; Varey, R.J. The service-dominant logic and the future of marketing. J. Acad. Mark. Sci. 2008, 36, 11-14. [CrossRef]

19. Payne, A.F.; Storbacka, K.; Frow, P. Managing the co-creation of value. J. Acad. Mark. Sci. 2008, 36, 83-96. [CrossRef]

20. Fischer, G.; Giaccardi, E.; Eden, H.; Sugimoto, M.; Ye, Y. Beyond binary choices: Integrating individual and social creativity. Int. J. Hum.-Comput. Stud. 2005, 63, 482-512. [CrossRef]

21. McColl-Kennedy, J.R.; Hogan, S.J.; Witell, L.; Snyder, H. Cocreative customer practices: Effects of health care customer value cocreation practices on well-being. J. Bus. Res. 2017, 70, 55-66. [CrossRef]

22. Lovelock, C. Services Marketing; Prentice Hall: Upper Saddle River, NJ, USA, 1996.

23. Vieder, J.N.; Krafchick, M.A.; Kovach, A.C.; Galluzzi, K.E. Physician-patient interaction: What do elders want? J. Am. Osteopath. Assoc. 2002, 102, 73-78. [PubMed]

24. Carman, J.M. Patient perceptions of service quality: Combining the dimensions. J. Serv. Mark. 2000, 14, 337-352. [CrossRef]

25. Coulehan, J.L.; Platt, F.W.; Egener, B.; Frankel, R.; Lin, C.; Lown, B.; Salazar, W.H. Let me see if I have this right ... : Words that help build empathy. Ann. Intern. Med. 2001, 135, 221-227. [CrossRef] [PubMed]

26. Gabbott, M.; Hogg, G. An empirical investigation of the impact of non-verbal communication on service evaluation. Eur. J. Mark. 2000, 34, 384-399. [CrossRef]

27. Mittal, B.; Lassar, W.A. The role of personalization in service encounters. J. Retail. 1996, 72, 95-109. [CrossRef]

28. La Rocca, A.; Snehota, I. Value creation and organizational practices at firm boundaries. Manag. Decis. 2014, 52, 2-17. [CrossRef]

29. Helkkula, A.; Kelleher, C.; Pihlström, M. Characterizing, value as an experience: Implications for service researchers and managers. J. Serv. Res. 2012, 15, 59-75. [CrossRef]

30. Hardyman, W.; Daunt, K.L.; Kitchener, M. Value co-creation through patient engagement in health care: A micro-level approach and research agenda. Public Manag. Rev. 2015, 17, 90-107. [CrossRef]

31. Gummerus, J. Value creation processes and value outcomes in marketing theory: Strangers or siblings? Mark. Theory 2013, 13, 19-46. [CrossRef]

32. Zainuddin, N.; Russell-Bennett, R.; Previte, J. The value of health and wellbeing: An empirical model of value creation in social marketing. Eur. J. Mark. 2013, 47, 1504-1524. [CrossRef]

33. Ng, I.C.; Smith, L.A. An integrative framework of value. In Toward a Better Understanding of the Role of Value in Markets and Marketing; Vargo, L.S., Lusch, R.F., Eds.; Emerald Group Publishing: Bingley, UK, 2012; pp. 207-243.

34. Aranburu, I.; Plaza, B.; Esteban, M. Sustainable cultural tourism in urban destinations: Does space matter? Sustainability 2016, 8, 699. [CrossRef]

35. Grönroos, C.; Gummerus, J. The service revolution and its marketing implications: Service logic vs servicedominant logic. Manag. Serv. Qual. 2014, 24, 206-229. [CrossRef]

36. Chandler, J.D.; Vargo, S.D. Contextualization and value-in-context: How context frames exchange. Mark. Theory 2011, 11, 35-49. [CrossRef]

37. Tregua, M.; Russo-Spena, T.; Casbarra, C. Being social for social: A co-creation perspective. J. Serv. Theory Pract. 2015, 25, 198-219. [CrossRef]

38. Porter, E.M. A strategy for health care reform-Toward a value-based system. N. Engl. J. Med. 2009, 361, 109-112. [CrossRef] [PubMed]

39. Wilson, A.; Zeithaml, V.A.; Bitner, M.J.; Gremler, D.D. Services Marketing: Integrating Customer Focus Across the Firm; McGraw Hill: Berkshire, UK, 2012. 
40. Chahal, H.; Kumari, N. Consumer perceived value: The development of a multiple item scale in hospitals in the Indian context. Int. J. Pharm. Mark. 2012, 6, 167-190. [CrossRef]

41. Jaakkola, E.; Halinen, A. Problem solving within professional services: Evidence from the medical field. Int. J. Serv. Ind. Manag. 2006, 17, 409-429. [CrossRef]

42. Young, T.; McClean, S.A. Critical look at lean thinking in healthcare. Qual. Saf. Health Care 2008, 17, $382-386$. [CrossRef] [PubMed]

43. Osei-Frimpong, K.; Wilson, A.; Owusu-Frimpong, N. Service experiences and dyadic value co-creation in healthcare service delivery: A CIT approach. J. Serv. Theory Pract. 2015, 25, 443-462. [CrossRef]

44. Aarikka-Stenroos, L.; Jaakkola, E. Value co-creation in knowledge intensive business services: A dyadic perspective on the joint problem solving process. Ind. Mark. Manag. 2012, 41, 15-26. [CrossRef]

45. Galvagno, M.; Dalli, D. Theory of value co-creation: A systematic literature review. Manag. Serv. Qual. 2014, 24, 643-683. [CrossRef]

46. Grönroos, C.; Voima, P. Critical service logic: Making sense of value creation and co-creation. J. Acad. Mark. Sci. 2013, 41, 133-150. [CrossRef]

47. Jaakkola, E.; Alexander, M. The role of customer engagement behavior in value co-creation: A service system perspective. J. Serv. Res. 2014, 17, 247-261. [CrossRef]

48. Osei-Frimpong, K. Examining the effects of patient characteristics and prior value needs on the patient-doctor encounter process in healthcare service delivery. Int. J. Pharm. Mark. 2016, 10, 192-213. [CrossRef]

49. Ballantyne, D.; Varey, R.J. Creating value-in-use through marketing interaction: The exchange logic of relating, communicating and knowing. Mark. Theory 2006, 6, 335-348. [CrossRef]

50. Prahalad, C.K.; Ramaswamy, V. Co-creating unique value with customers. Strateg. Leadersh. 2004, 32, 4-9. [CrossRef]

51. Alejandro, T.B.; Kowalkowski, C.; Ritter, J.; Marchetti, R.; Prado, P. Information search in complex industrial buying: Empirical evidence from Brazil. Ind. Mark. Manag. 2011, 40, 17-27. [CrossRef]

52. Moller, K.; Torronen, P. Business suppliers' value creation potential: A capability-based analysis. Ind. Mark. Manag. 2003, 35, 913-924. [CrossRef]

53. Shafei, I.; Walburg, J.A.; Taher, A.F. Healthcare service quality: What really matters to the female patient? Int. J. Pharm. Mark. 2015, 9, 369-391. [CrossRef]

54. Storbacka, K.; Nenonen, S. Customer relationships and the heterogeneity of firm performance. J. Bus. Ind. Mark. 2009, 24, 360-372. [CrossRef]

55. Gill, L.; White, L.; Cameron, I.D. Service co-creation in community-based aged healthcare. Manag. Serv. Qual. 2011, 21, 152-177. [CrossRef]

56. Wu, C.H.-J.; Liang, R.-D. Effect of experiential value on customer satisfaction with service encounters in luxury-hotel restaurants. Int. J. Hosp. Manag. 2009, 28, 586-593. [CrossRef]

57. Dagger, T.S.; Sweeney, J.C.; Johnson, L.W. A hierarchical model of health service quality scale development and investigation of an integrated model. J. Serv. Res. 2007, 10, 123-142. [CrossRef]

58. Hsieh, E.; Ju, H.; Kong, H. Dimensions of trust: The tensions and challenges in provider-interpreter trust. Qual. Health. Res. 2010, 20, 170-181. [CrossRef] [PubMed]

59. Godolphin, W. Shared decision-making. Healthc. Q. 2009, 12, e186-e190. [CrossRef] [PubMed]

60. Elwyn, G.; Coulter, A.; Laitner, S.; Walker, E.; Watson, P.; Thomson, R. Implementing shared decision making in the NHS. Br. Med. J. 2010, 341, 971-973. [CrossRef] [PubMed]

61. Aveling, E.-L.; Martin, G. Realising the transformative potential of healthcare partnerships: Insights from divergent literatures and contrasting cases in high-and low-income country contexts. Soc. Sci. Med. 2013, 92, 74-82. [CrossRef] [PubMed]

62. Moeller, S.; Ciuchita, R.; Mahr, D.; Odekerken-Schröder, G.; Fassnacht, M. Uncovering collaborative value creation patterns and establishing corresponding customer roles. J. Serv. Res. 2013, 16, 471-487. [CrossRef]

63. Hughes, S. The use of non face-to-face communication to enhance preventative strategies. J. Cardiovasc. Nurs. 2003, 18, 267-273. [CrossRef] [PubMed]

64. Loden, J.; Schooler, C. Patient compliance. Pharm. Exec. 2000, 20, 88-94.

65. Say, R.E.; Thompson, R. The importance of patient preferences in treatment decisions-challenges for doctors. Br. Med. J. 2003, 327, 542-545. [CrossRef] [PubMed]

66. Mohr, J.; Nevin, J.R. Communication strategies in marketing channels: A theoretical perspective. J. Mark. 1990, 54, 36-51. [CrossRef] 
67. Holbrook, B.M. Rosepekiceciveci versus CCV: The resource-operant, skills-exchanging, performance-experience, knowledge-informed, competence-enacting, co-producer involved, value-emerging, customer-interactive view of marketing versus the concept of customer value: "I can get it for you wholesale". In The Service-Dominant Logic of Marketing: Dialog, Debate, and Directions; Lusch, R.F., Vargo, S.L., Eds.; MS Sharpe: New York, NY, USA, 2006; pp. 208-223.

68. Gallan, A.S.; Jarvis, C.B.; Brown, S.W.; Bitner, M.J. Customer positivity and participation in services: An empirical test in a health care context. J. Acad. Mark. Sci. 2013, 41, 338-356. [CrossRef]

69. Chan, K.W.; Yim, C.K.; Lam, S.S.K. Is customer participation in value creation a double-edged sword? Evidence from professional financial services across cultures. J. Mark. 2010, 74, 48-64. [CrossRef]

70. Crosby, K.L.; Evans, K.R.; Cowles, D. Relationship quality in services selling: An interpersonal influence perspective. J. Mark. 1990, 54, 14-22. [CrossRef]

71. Janz, N.K.; Becker, M.B. The health belief model: A decade later. Health Educ. Q. 1984, 11, 1-47. [CrossRef] [PubMed]

72. Bogart, L.M.; Bird, S.T.; Walt, L.C.; Dalahanty, D.L.; Figler, J.L. Association of stereotypes about physicians to health care satisfaction, help-seeking behavior, and adherence to treatment. Soc. Sci. Med. 2004, 58, 1049-1558. [CrossRef]

73. Cheng, S.H.; Yang, M.C.; Chiang, T.L. Patient satisfaction with and recommendation of a hospital: Effects of interpersonal and technical aspects of hospital care. Int. J. Qual. Health Care 2003, 15, 345-355. [CrossRef] [PubMed]

74. Gummerus, J.; Pihlstrom, M. Context and mobile services' value-in-use. J. Retail. Consum. Serv. 2011, 18, 521-533. [CrossRef]

75. Sirgy, M.J. The Psychology of Quality of Life; Kluwer: Dordrecht, The Netherlands, 2002.

76. Fornell, C.D.; Larcker, F. Evaluating structural equations models with unobserved variables and measurement error. J. Mark. Res. 1981, 18, 6-21.

77. Bagozzi, R.P.; Yi, Y. On the evaluation of structural equation models. J. Acad. Mark. Sci. 1988, 16, 74-95. [CrossRef]

78. Cronin, S.N. Health beliefs in compliant and noncompliant hypertensive clients. J. Commun. Health Nurs. 1985, 3, 87-97. [CrossRef] [PubMed] 